\title{
The Role of Changing Management in the Process Of Enhancing the strategic Marketing Planning in Jordanian Industry Sector (Model-Complement)
}

\author{
Salman Mohammad Abulehyeh ${ }^{1}$ \& Ali Falah Al-Zoubi ${ }^{1}$ \\ ${ }^{1}$ Faculty of Business, Arab Amman University, Jordan \\ Correspondance: Salman Mohammad Abulehyeh, Assassinate Prof of Marketing, Faculty of Business, Arab \\ Amman University, Jordan. E-mail: alzoubifali@yahoo.com
}

Received: January 9, 2017

Accepted: April 2, 2017

Online Published: April 27, 2017

doi:10.5539/ijbm.v12n5p130

URL: https://doi.org/10.5539/ijbm.v12n5p130

\begin{abstract}
This study examines the role and importance of change management in enhancing and managing strategic marketing planning related to strategic problems characterized by depth and complications. This rather planning demands extensive and deep research concerns variables and capabilities of futuristic analysis of propositions and probabilities. Thus, planning designers are the critical suppliers to the organization. The importance of studying change management is stressed, as well as its role in enhancing the process of strategic planning which is essential for the organization in the future. This is the main subject of this study. A matrix including several variables has been set, being one of the tools of marketing strategic planning for the organization. These variables decide the extent of market attraction and its competitive position in different market situations. Additionally, another matrix was set up to determine the competitive capability of the organization. On this basis, the suitable investment strategy has been determined, according to each market situation, in relation to market attraction \& the competitive capability of the organization. After finishing the marketing revision, evaluation of the organization's internal situation has been done as to the threats and opportunities in comparison to opportunities and threats in the external environment. Good management and investment in change management employed by food companies in the private Jordanian sector is still limited due to obstacles, limitations related to managers and leaderships as well as present technical, financial, and information capabilities.
\end{abstract}

Keywords: change management, strategic marketing planning, industry sector, Jordan

\section{Introduction}

Therefore, the ability of administrative sciences to keep up with these accelerated changes is called "Changing Management" because change is one of life's characteristics generally and one of twenty-one centaury's characteristics particularly. Hence, the administrative sciences have to be developed and reconsidered to keep up with new changes through taking advantage of change and avoiding its disadvantages in all economic, social, political, technical, educational, intellectual, religious and informational aspects because informed management is able to keep up with changes in its communities and in the world.

The changing management represent one of scientific branches, which is, still received a great attention by specialists and decision-makers in Jordanian business organizations and companies. In addition, it is considered an important integrated part in administrative systematic model which should be practiced in them and which is based on knowledge, information and managing them effectively. In light of advanced information systems related to support administrative decision, the development mechanism is no longer concealed in Know-How, which is accessed, by specific administrative equations but the ability to make sure that these equations represent methods of act which have to take into consideration and which are consistent with facts the developed dynamic reality provides to industrial environment. From there, the ability of management and its effectiveness in the company depend largely on the changing management because possessing knowledge of these changes and the ability to employ them appropriately in order to look for solutions are considered two main themes of strategic management (Al-Zoubi, 2015).

Planning constitutes an important aspect of effort, which the management should pay attention to. The proper management requires making series of decisions related to determine objectives, which seek to achieve, and then, 
develop and set out programs and plans to ensure achieving these objectives. When the process of planning is related to future, forecasting is considered a core of this process. Therefore, it should depend on the level of information by which the planner can make future scenarios that enable him to set out potential methods of act regarding these changes. Accordingly, the management has to play a distinctive role in achieving the levels of desired performance.

\section{First Topic: Entrepreneurship Methodology in Changing Management}

\subsection{Definition of Changing Management}

The changing management means the ability of administrative methods to face self-internal and accelerated external changes. This happens by a number of defensive methods as a reaction of changing processes; which means waiting until change happens, and then searching about how to deal with it. Furthermore, it happens according to the expectations of changing through future quest and pre-readiness to deal with them: whether by acceptance or rejection according to quantity of collected data, its accurate scientific analysis, ability to make decisions rapidly and determinately by accepting change in specific phases or rejecting in acceptable logic, and involving all available competencies in making decisions, noting that the wary of changing is considered a human feature because human being familiarizes what he is used to and fears from changing, particularly if it has conducted suddenly (Kyle Bagwell \&Robert. W. Stagier, 2009)

The changing management also means a planned change, which intends to improve the effectiveness of management and enhance the possibility of overcoming problems this management faces. In addition, it is considered a long-term plan to improve management performance in the way it solves its problems, and renews and changes its administrative practices. This plan relies on corporative effort among managers, taking into considerations environment, which the management works in, intervention of third party and scientific application of behavioral sciences. (Kotler, Philip, 2012)

\subsection{The Changing Management Elements}

The changing management includes the following elements: (Al-Zoubi, 2015)

1. Long-term plan: it cannot be expected changing or developing in objectives, plans and practices of management rapidly; the process of setting out the development plan takes at least one year.

2. Solving problems and renewing practices: our objective is strengthening the efforts of management to face its problems. These problems are faced through developing biased method for management to solve problem and adapt with changed circumstances of environment surrounding this management.

3. Collaborative effort of managers: regardless who makes the development decision; there are phases, which requires collaborating among managers as well as developing the bonds of communication and coordination among them. Managers have to be convinced that any problem in the management is considered a problem of management as a whole and not a problem related to part of it.

4. Influencing by the environment of management: Setting out a distinctive method to solve problems and renew the practices of management should be based on understanding the elements of environment, which the organization works in, as well as understanding how the environment influences on its practices.

5. External intervention: For example, the external party diagnoses problems, trains those who develop themselves, solve their problems and suggests some development methods.

6. Scientific application of behavioral sciences: it means that the organization is based in its development efforts on collecting information regarding problems, depending on the experience of external consultants, relying on the participation of managers in setting out solutions and collecting information continuously regarding applying and evaluating new development methods.

\subsection{Change Management Requirements}

Accordingly, the successful changing management requires understanding the following: main types of change how change influences on individuals, change process and how to commit to the change. (Kotler, Philip, 2012).

\subsection{Types of Change}

There are two main types of change including:

- Strategic Change: The strategic change takes into consideration long-term main issues, which the institution keeps attention. It is a step for future, therefore, it can be defined generally by the term of strategic vision including: the objective of institution as well as its joint mission and philosophy regarding growth, quality, innovation and values which are related to workers, needs of beneficiary groups and used techniques. This 
comprehensive definition leads us to determine the characteristics of competitive positions through enhancing these objectives by the police related to marketing, sales, manufacturing, processing and developing products, financing and managing affairs of individuals. The strategic change takes place within the scope of several factors including external environment and internal resources of institution, abilities, culture, structures and systems. Hence, the institution requires implementing the strategic change successfully through fully analyzing and understanding these factors in two phases including configuration and planning. (Drucker, Peter, F. ,2009)

- Job Change: The job change is related to new systems, procedures, structures and techniques, which have a direct impact on work organizations inside any sector of institution. These changes may have larger impact on workers than strategic changes; therefore, we should deal with these changes carefully.

\subsection{Reasons of Development and Change}

The reasons which force administrations in industrial companies in Jordan to conduct development and change in their parts can be summarized into that there are surrounding problems and changes and that it cannot be solved these problems or kept up with surrounding changes unless some changes takes place in the parts of administration as well as in the method which you think about to overcome its problems. These reasons can be transferred into objectives such as:

- Examining growth or deterioration of management and surrounding opportunities continuously.

- Developing the methods of management in overcoming problems, which it faces.

- Increasing trust, respect and interaction among the individuals of management.

- Increasing enthusiasm and ability of management's individuals in overcoming their problems and in their self-discipline.

- Developing leaders who are desired and able to carry out the administrative creativity.

- Increasing the ability of management to maintain the origins of distinctive qualities of company's individuals, groups and administrations.

- Establishing biased atmosphere for developing and creating. (Drucker, Peter, F., 2009)

\subsection{Change and Its Reactions}

Reactions of people resulting from sudden changes around them vary. It can be distinguished among several phases, which reactions go through. These phases are: (Al-Zoubi, 2015)

- Shock: it indicates acute feeling of unbalance and inability to act.

- Unbelieving: feeling that the reason is unrealistic and non-objective in emerging change.

- Guilt: Individual's feeling of making a mistake, which requires change that has happened

- Censure: Individual censures another due to change that has happened.

- Justification: Individual sets out some reasons of change.

- Complementarily: Individual adapts the change and transfers into advantages which individual or system benefits from.

- Acceptance: The enthusiasm of individual is subject to new situation after changing.

\subsection{The Causes of Resistance to Change}

- When you are the goals of the change is not clear.

- When the persons affected by the change is not involved in it.

- When you persuade others to change based on personal reasons.

- When ignore the traditions, patterns, and labor standards.

- When there is a weak connection or missing on the subject of change.

- When there is a fear of the results of the change, or the threat of personal interests.

- When there is a change fails.( Leontiasis, Milon ,2012)

\subsection{Methods Change Management}

- adopt the methodology of research and development continued unabated

- Taking ways economic analysis; and advanced statistical systems and renewable information. 
- Keep pace with the times in systems design; planning; and software configuration; and follow-up; and good evaluation.

- Good look to the future and possible changes in it.

- Adoption of the available information on the local and global management systems; government regulations and environmental potential mainly administrative planning.

- Adopt the role of the human element primarily as a role in the management process.

- Concern for the distribution of competence; centralized authoritarian and avoid; with conscious vigilance control; and continuous follow-ups to achieve, the fulfillment of the requirements of working in an atmosphere of the right human relations and this is the role of adult administrative leadership. (Leontiasis, Milon, 2012)

\subsection{Who Is Development?}

There are three alternatives in this regard:

\section{1. senior management.}

- Changing individuals.

- Change groups.

- Changing organizational structures.

2. The Participation. Be one of the following two forms:

- Collective decision-making: The senior management here diagnose problems, defined, and studied, and you select alternatives solutions. The senior management to give guidance to the lower levels to consider these alternatives and choose the most appropriate alternative to it follows this. Here are the workers to do their best in the study of alternatives, choose that alternative that suits them, and solve their problems.

- Solving problems collectively: This method in participation is stronger and deeper, and that's because the workers are not only studying the alternatives and choose the most suitable one, but it extends to study the problem, gather information about it, and defining the problem accurately, and come up with alternatives for disposition and solution. (Leontiasis, Milon ,2012)

3. Authorization, the organizational levels and workers are authorized with one of these following methods: (Joselyn, Robert, W. and Humphries, Keith, D.,2011)

- Discuss the situation: a problem is taken from one of the departments or sections as a case of discussing, the administration manager or head of the department guide the discussion between employees, this is done for the purpose to make the employees acquire the skill of studying their problems, and introduce information that may be useful in solving the problem. Thus, the intervention of the manager or president is not to impose certain solutions, but rather to encourage workers to get solutions on their own to their problems.( Kyle Bagwell \&Robert W Stagier ,2009)

- Sensitivity training: And here, employees are trained to be more sensitive to the behavior of individuals and groups that are dealing with, and focus on the basis for the behavior of individuals and groups that they are dealing with. In addition, the focus is mainly on workers to acquire the skill of self-Insightfulness and awareness of what is happening around them. In addition, preparedness and sensitivity to the feelings and behavior of others. (Ali AL-Zoubi ,2017 )This approach relies on a basic assumption is that the acquisition of behavioral skills required of employees and their sensitivity to the feelings of others and to the problems of workers. Work can be developed to become better, this means that organizational development depends largely on the development of relations and personal skills for workers. How can we judge the methods preference? However, the question will not be answered except in accordance with certain criteria, such as:

1. Satisfaction of employees affected by the change.

2. The speed of change.

3. The immediate and short-term results.

4. Long-term results.

5. Resistance to change.

6. Commitment to change.

7. Innovation and constant creativity.(Joselyn, Robert, W. and Humphries, Keith, D.,2011) 


\subsection{What Is Being Developed and Changed?}

- Individuals.

- work groups . The plan of organizational development includes the next steps:

- Initial diagnosis and it starts with interviews between the manager and employees.

- The formation and training of the study teams in training programs aimed to raising individual and collective skills in communication.

- Collecting and discussing data.

- Making a change plan.

- Building work teams.

- Development of social relations.

- Implementation or application of the change and follow-up. (Al-Zoubi, 2015)

\subsection{Search Model}

The effectiveness of strategic planning in the industrial market is based on the existence of an effective system that provides a high quality knowledge base of the variables of industrial market and effective major powers influencing it and the interactions between these forces. Bridging the gap of changes between perceptions of the company's management and scenarios resulting from the movement of those forces would support the administration's ability to look to the future and predict what can happen in it. Therefore, the changing management and within this framework will raise the level of the planning process and lead to the improvement of the quality of decisions associated. Thus, the effective management of changes in the company requires doing two basic jobs:

1. Provide a renewed and sustained base of information about the variables.

2. Employing this base in the analysis and interpretation of events and changes around it, helping to make appropriate marketing decisions.

The systematic processing of the stock of knowledge of changes accumulated enables the company's management to answer the following axial questions: (Ali AL-Zoubi ,2016 )

- What is happening around it?

- Why it happened?

- What is the method of acting to be applied to face what happened?

- What are the effects that can be produced from what happened?

- What are the methods of acting to face the possible effects?

The first question involves attempt to identify and clarification; it includes the classification and analysis. It is the way with which to achieve control and confirmation of its standards, and help to answer this question on setting priorities behaved, and determine time scales for all actions to be taken. The second question, it refers to the logical and analytical thinking that is based on the problems linked to what could be the reasons they occur. That kind of thinking does not stop in administration when noticing problems, but to identify the underlying causes, thus, it will be able to take the most appropriate actions to address the problems or minimize their effects. The rest of the questions are related to what procedures they must do, it involves a rational selection process enables management to select the most appropriate alternatives available at the lowest cost. This research sheds light on the strategic marketing planning in companies, and suggests in that framework an integrated model depends on the effective management of the changes available to companies. Figure 1 illustrates a model of integration between change management and strategic marketing planning process. 

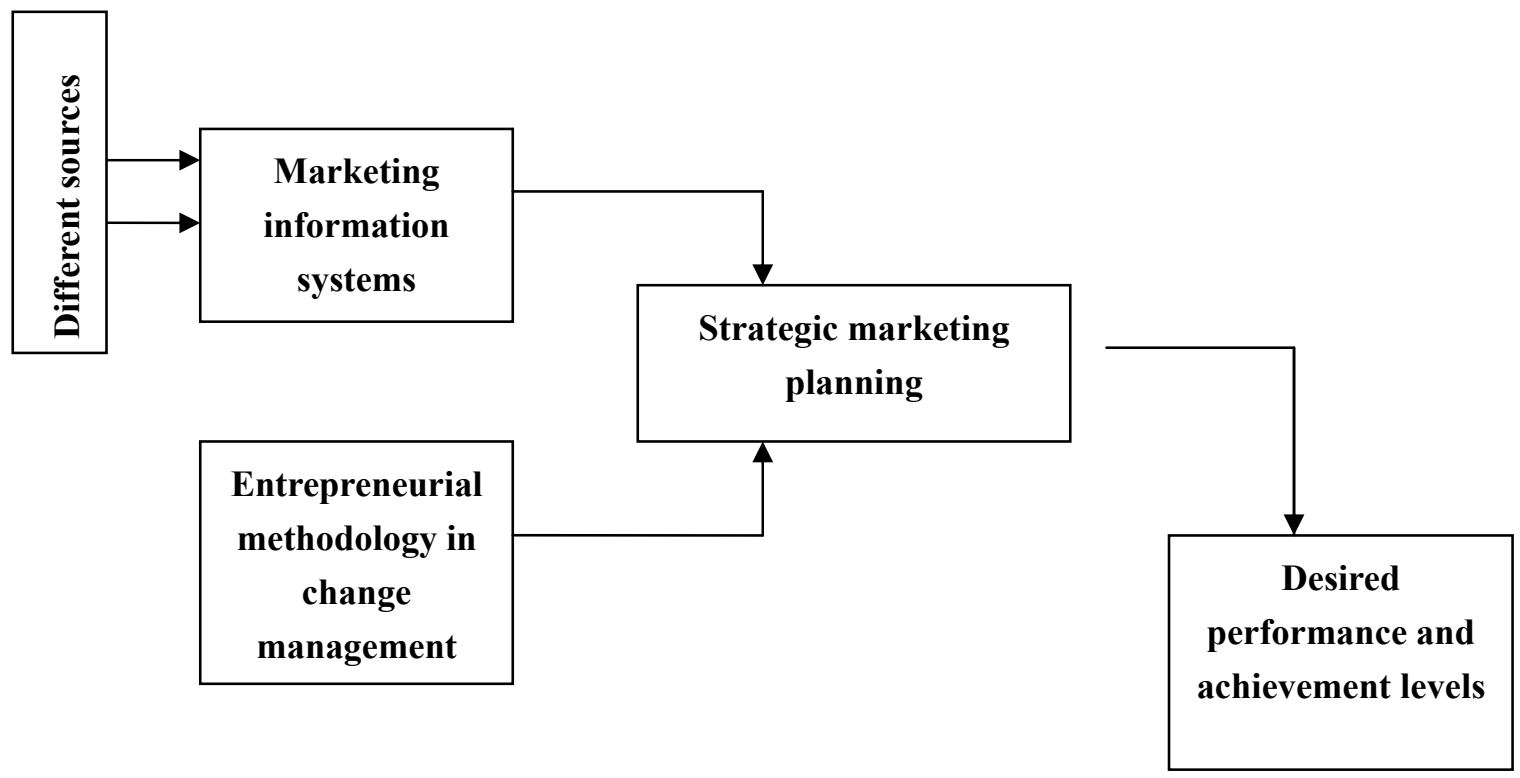

Figure 1. General model for integration between change management and strategic marketing planning Source: (prepared by researchers, 2016)

The administrative change means moving from position to another to be the best and most productive and performers, this change needs a momentum that facilitates all consecutive stages and being able to reach its goals, but that may emerge a reverse movement that rejects this change and tries to stop it and to keep the situation as it is. This current is called resistance to change.

\section{The Second Topic: The Importance of Strategic Marketing Planning for the Company}

\subsection{The Concept of Strategic Marketing Planning}

The strategic industrial planning is defined as the administrative activity associated with the process of identifying the main objectives of the company's management, which seeks to achieve and identify alternative disposition methods by which to reach those goals with the best means and lower costs. This involves a rational process aimed at studying and analyzing each of these methods and evaluated based on their contribution to achieving the goals, leading in the end to choose the most appropriate method. In addition, the marketing planning process in the company takes a strategic dimension when the resources and capabilities available are limited to the management. While the environment in which the company operates imposes, many variables that are not being able to controlled the company's management. In this case, the task of managing the company is concentrated in trying to apply their resources in these areas and aspects of the activity in which can maximize their revenues. In addition, of course, it would require the need to adopt a methodology for achieving those goals whatever it needs to organize and coordinate all the efforts exerted in this direction, and the activation of the possibilities and capabilities of mental and physical existing in it. (Al-Zoubi, 2015)

Moreover, the fact is, marketing planning logic depends on creative thinking and dynamic renewable, specially once we realize the changing nature of the effective powers in the ongoing events happening in the company's environment. This underlines the fact that the management adoption of marketing planning as a methodology of work does not necessarily mean that following the style of acting can always be the road to success and in all other situations, which requires the management of the company a high degree of flexibility and the ability to adapt to each situation individually so that it can respond to its requirements and respond to it. This would lead to logical solutions to certain problems, therefore, the strategic planning is for the management of the company, the tool by which that can cope with the requirements of the change in the surrounding environment and adapt to them down to the survival and continuity. From this standpoint, marketing planning helps the company's management in recruiting and directing available resources with high efficiency.( Ali Al-Zoubi and Adel Anzi ,2016) 


\subsection{The Importance of Planning in Industrial Marketing}

The concept of marketing planning involves in the process of determining the activities the company's management should do and implementing those activities. Here lies the importance of the role of planning in enabling the management to control the factors affecting the results that can produce marketing activities undertaken by the management, in addition, planning helps to guide these activities in directions that raise the possibility of achieving the desired goals. Thus, the essence of the strategic planning process lies in the company's management attempt to bring a kind of matching and alignment of resources and capabilities available to the Company and the surrounding environmental conditions, down to the type of creative wording that helps the company achieve the right adaptation with the environment, as noted previously, the most important characteristic of the environment is constantly changing with everything produced by this change of data that makes the process of forecasting and predicting a difficult task, Which imposes on the company's management a new style of management methodology to ensure its proper employment of available resources. (Ali Al-Zoubi \& Adel Anzi ,2016)

If the movement of market forces as a key determinant to the trends of management and its ability to make decisions closely influences companies from most types of economic institutions, it creates a sufficient justification to follow the logic of planning in the industrial marketing processes. Given the industrial market is characterized by the dynamic needs, goods and services to individuals and institutions making up this market, considering that the development of these needs is linked to the development of many economic, social, cultural, political and environmental factors, the survival of a company in such a market would be subject to its ability to produce goods and services that meet the needs of goods and services secreted by the market. The goal of profitability which companies strives to achieve stems from the company's management's ability to achieve the highest levels of satisfaction to those needs, this trend in industrial management thinking dictates the company's management a greater degree of interaction with the markets they serve, and to enable it to identify opportunities to survive. (Ali AL-Zoubi ,2016)

In addition, the complexity resulted in export and international trade and what it involves of financial and credit operations to increase the importance and seriousness of the role played by these companies in financing these operations and their coverage. Entering of this international dimension in industrial processes has resulted to increase the complexity of the tasks upon the company's management, the transfer of its interest from a limited circle to a larger scale, which required the company continuous planning to meet the new conditions and handling them. Strategic planning helps to outline and identifies tracks of high-priority which the company's management must adopt so that it can achieve profitability target rates, thus, the planning process requires a lot of integration and coordination between efforts and at all work levels in the company.( Bilal Alsakarneh ,2010).

\subsection{Advantages of the Strategic Marketing Planning}

Kotler explained the advantages of strategic planning in marketing as follows:

- Assist in the achievement of the basic objectives of the company and to identify ways and means to do so.

- Build team spirit; as the planning process requires much effort from individuals and departments within the company, and access to the plans and programs of work requires a lot of coordination between these efforts, allowing a better atmosphere for cooperation and consultation, which ultimately leads to the development of team spirit within the company.

- Strategic planning provides a deeper level of understanding and awareness of many aspects of industrial work leading to enrich the knowledge of those responsible for planning and generate a higher degree of commitment for the work requirements, which in turn leads to give a great deal of realism to the plans that are prepared.

- Generate a common sense among those who are responsible planning process of the importance of the purpose and the need to achieve and adhered the fundamental objectives of the company. This helps to increase the sense of the importance of integration in the administrative work.( Ali Al-Zoubi and Adel Anzi ,2016)

\subsection{The Characteristics of a Good Marketing Plan}

Writers and thinkers in the field of management differed to determine what could be termed as good marketing plan properties. They were unanimous in four of them, which are:

- Flexibility: The plan must be flexible enough to be adjusted and adapted to the emerging situation, to accommodate the changes incurred by unforeseen developments during implementation. 
- Unity: This means that the Company has to have a consolidated comprehensive plan to be implemented at all levels of the business and simultaneously.

- Continuity: This means that the strategic plan should have a continuity and communication mechanisms with the passage of time, so that it can achieve long-term goals.

- Accuracy: it requires the presence of regular working methods, in addition to the need to provide measurement tools and standards for the proper evaluation of all aspects of the activity carried out by the company. (Al-Zoubi, 2015)\& ( Bilal Alsakarneh ,2010)

\subsection{Components of Strategic Marketing of the Company}

Marketing strategy of the company is made up of the following elements :( Derek, F. Channon, 2009)

- The primary task: The plan must specify the primary task to manage the marketing at the company originally stemming from the task which the company was created for.

- Marketing main objectives of the company: These goals show a group of results the company's management should make sure to achieve in the future, and these goals should be put in a way that can be measured.

- Certain assumptions about the surrounding environment and in particular the industrial market: This includes clear statements about future trends in strategic sectors in the market.

- Assess the competitive strength of the company: Strategic marketing must involve a realistic assessment of the areas of strength and weakness for the factors that affect the company's ability to achieve its objectives in light of the expected market conditions.

- Evaluation of potential opportunities in light of data secreted by the environmental analysis: It must be done for each of the areas of marketing activity and the level of each commodity of industrial goods provided to its customers, and within this framework, the company's management should seize the opportunities available in order to determine disposition methods and actions that should be done down to the desired achievements.

- Determine business strategies specific of each activity of the marketing activities of the company as well as specific for each sector of customer sectors and the objectives to be achieved in the area of each activity.

- The company's management can control the expected strategic changes in the factors of external environment for the company and that. (Bilal Alsakarneh ,2010)

\subsection{Requirements of Effective Marketing Planning}

In Reality, there is no ideal marketing planning in companies. Perfect planning in a company is the one that suites its reality and the requirements of implementation. This planning must consist with the strategies of the company's administration, its organizational structure and the company's institutional culture. In fact, what planners do traditionally in companies is not enough and does not even rise up to the level of the challenges imposed by advancement in the surrounding environment. Moreover, many of those planners have strong reservations about its importance for them and their companies. The provision of a better atmosphere for strategic marketing planning lies in the presence of a number of requirements mentioned as follows:

1. Acknowledgment of the need for planning: Successful marketing planning requires full acceptance of importance of planning and the urgent need for it by marketing staff. Such an acceptance would increase the attention paid by the company's management to planning. In general, realizing the need for planning results usually from the following factors.

Adeline in company is marketing performance: when company's marketing performance start to decline, compared to other competing companies, pressure from higher management will increase in order to regain the relative position of the company in the market. As the relative deterioration in the performance of Chase Manhattan Company compared to City Bank in mid-seventies led to the adaption of strategic planning by the first board of directors through importing necessary experiences from General Electric.

Pressure imposed by the success of competition: Distinctive marketing performance of competitor companies usually evokes responses of the company's administration in which strategic planning is considered one of the approaches to confront those competitors.

C. Sudden losses in the company: When the company faces an unexpected lose; the company's administration has to make the necessary change in the followed supervision system to prevent such incidences from happening. (Al-Zoubi, 2015) 
D.Strategic shocks: A company may go through a strategic shock when it faces an unexpected important event at time in which the company's administration had not made procedures to avoid it. This way, planning becomes the method of overcoming crisis.

2. The commitment of company's administrative leadership: without the evident commitment of the company's general director to the adaption of planning as a methodology for work, no planning efforts would succeed. The planner needs constant support and backing from higher administration including the provision of necessary machines to collect the needed information for creating programs and plans, legalizing them and making them creditable thus causing commitment in implementation on all levels by individuals. (Porter, M.F.,2011)

3. Reorganization: the integration of strategic planning system into the company's marketing activity would Supply those in charge of this activity with tools and suitable means to implement the plans and programs, which resulted from the planning process. The implementation of strategic planning as a methodology for work by marketing management in the company would widen its horizon to recognize different marketing activities in the company and responsibilities entailed that can be used to delegate authorities to view them until reaching a kind of balance between authority and responsibility in performing these activities in a way that retains the balance and cohesion of the company's organizational structure. (Mcnurlin, B. and Sprague, R., 2011)

4. Provision of sufficient database: the main problem always facing planning efforts is the need for sufficient information that helps the planner in drawing internal and external environmental scenarios for the company thus creating suitable plans and programs to deal with these scenarios. Good information helps in achieving the following: clear definition of the industrial market, Market distribution,Measurement of market attractiveness ,Determination of the company's competitive situation, Analysis of the profitability of industrial processes on the level of the client and the industrial commodity, Evaluation of the necessary strategic resources' requirements including (Human and financial resources and systems),Design of effective control systems ,Development of suitable reward systems, Making suitable organizational change

\subsection{Analysis and Marketing Audit}

Marketing Audit in a company aims at collecting all necessary data to identify the method that will enable the company to succeed in marketing every single industrial commodity presented to all served client segments. This data is collected throughout comprehensive evaluation and auditing process of overall environment under which the company operates and its internal environment. This process includes four essential domains as follows:( Porter, M.F.,2011)

\subsubsection{Analysis of the Environment, Including}

- Analysis of Internal Environment: This includes conducting a realistic analytical study on the capabilities and resources of the company as well as the sources of its strengths and weaknesses. It also includes Analysing previous accomplishment of the company, problems encountered and actions taken to deal with these problems and solve them. The company's records are considered a huge resource of information, which the marketing management needs, in the planning process. There is a massive information storage in every company about clients, such as their characteristics, the volume of their operations with the company and even the approach to dealing with them. The company's records also include sufficient information about markets and trends of the investment company. In the light of this information, the marketing management in the company can recognize available opportunities; determine the company's ability to seize it and the potential obstacles in this regard. (Baker, Michael, J.,2011)

- Analysis of External Environment: Porter explained that the essence of strategic planning lies in connecting the company with the environment in which it operates. Since companies work under dynamic market circumstances, it is vital for company's administrations to conduct a study and an analysis on the surrounding external environment.

Economic Environment: it includes the analysis of economic situation with all its indicators. Generally this analysis includes: The general economic situation (recovery/ recession) - inflation rates - trends in priceIncome levels and its distribution- interest rates and its trends- rates of general economic growth - the dominant competitive model in the market.

Social and cultural environment: This factor in the surrounding external environment has an important impact on the company's strategic marketing planning and design. This analysis includes Life style of community members - prevailing traditions and norms - social and religious beliefs and values - awareness and 
cultural level in society - individual trends towards development and accepting its elements - common sense and individuals' preference levels. (Marsh, J.R.,2012)

- Political and legal environment: This may be the most important aspect of the surrounding external environment in the company and the most influential on its operations. This analysis includes Regulations, laws and legislation in force - general fiscal and monetary policy- international relations that connect a country to other countries.( Baker, Michael, J.,2011)

Technological environment: This factor has a huge importance in the company's marketing operations. It is worth mentioning that there is growing trend among companies in mechanization of many industrial commodities such as, ATMs, talking bank, in addition to the necessity ,acknowledged by the company's administration, to consider and implement technology that was imposed by the usage of computers in order to achieve fast and better commodity for clients. Strategic marketing planning in a company depends extensively on these factors and to which extent the administration realizes the importance and aspects of the impacts that may affect its operations and performance methods. Figure 2-Industrial environment and its relation to marketing strategy in the company. Figure 2.

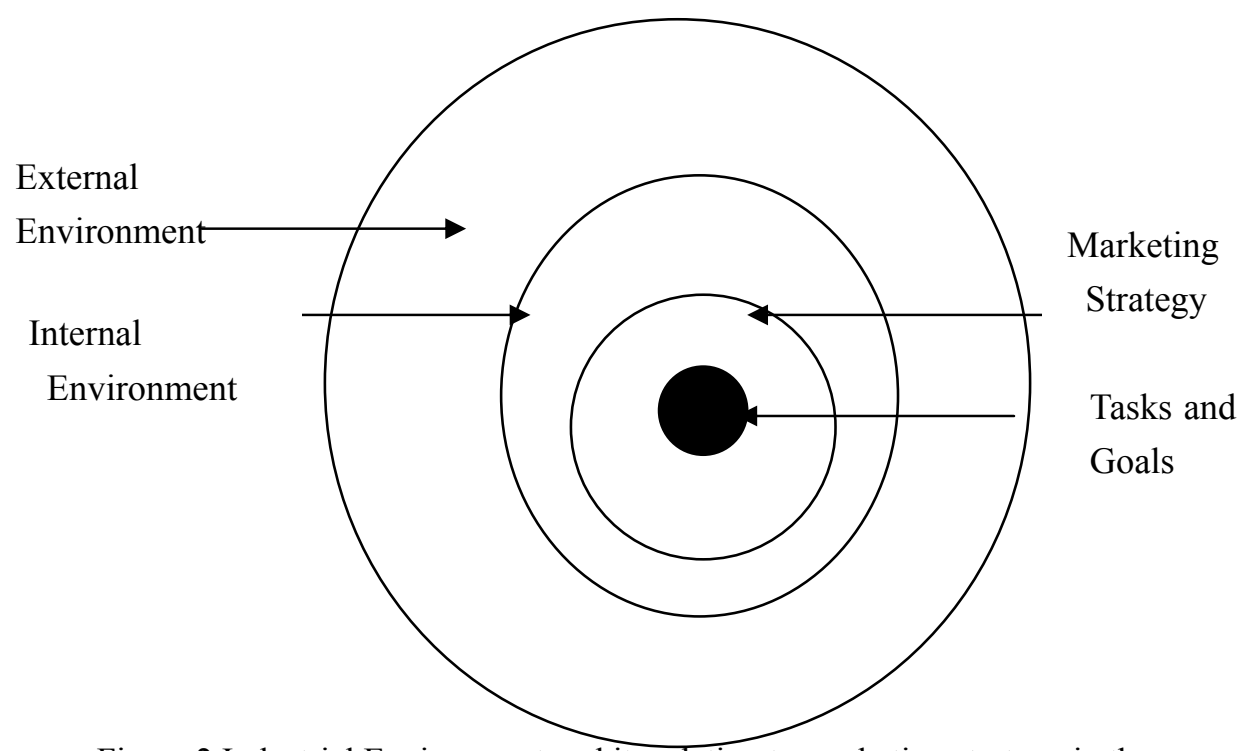

Figure 2.Industrial Environment and its relation to marketing strategy in the company

\subsubsection{Analysis of the Market and Identifying the Company's Competitive Situation}

The matrix of multi factors profile is considered one of the strategic marketing planning is tools in the company. Building this matrix depends on determining a number of factors that can determine the extent of the market attractiveness and competitive position in various market conditions. It is considered a guide for action for the company's marketing management to be used in the analysis of the market and to determine the attractive and down to determine the competitive position in the company. Therefore, this matrix must be built this because of precise criteria. Table (1) The matrix of factors that determine the attractiveness of the industrial market and its relative weights, in addition to the group of factors determining the competitive position of the company.

Table 1. Matrix of identified factors for market attractiveness, the company's competitive condition and their relative weights

\begin{tabular}{ll}
\hline Factors & Relative weights \\
\hline Identified factors for market attractiveness & \\
$-\quad$ Overall size of the market. & 25 \\
$-\quad$ Annual market growth rate. & 20 \\
$-\quad$ Historic margin of profit. & 15 \\
$-\quad$ Competition severity. & 25 \\
- Other factors. & 15 \\
\hline
\end{tabular}




\section{Total}

Specific factors for the company's competitive position:

-market share

- Market share growth.

- Other factors.

Total

\section{0}

20

20

60

100

After building this matrix, another matrix is built to identify the company's competitive ability according to the following technique:

- Identification of factors that reflect the competitive condition of the service in its market and the degree of this market's attractiveness.

- Identifying the relative weight of each factor

- Identification of the company's ability for each factor on a five-grading scale (1-5), so that number (1) refers to very weak, and number (5) to very strong.

- Identifying any political, social or legal factors that could affect the competitive position of the company in the market, so that all of these factors are evaluated based on acceptance or rejection.

- The relative weight of each factor is multiplied by the degree of strength of the company related to this factor, which ranges between (1-5) to reach the approved measure. Table No. (2) Is the company's competitiveness matrix.

Table 2. The company's competitiveness matrix

\begin{tabular}{llll}
\hline Factors & Relative weight (A) & Degree (B) & Measurement (AxB) \\
\hline Specific factors of market attractiveness: & & 3 & 0.75 \\
- Overall size of the services' market. & 0.25 & 5 & 1.00 \\
- Annual growth rate of the services' market. & 0.20 & 5 & 0.75 \\
- Profit margin. & 0.15 & 2 & 0.50 \\
- The intensity of competition. & 0.25 & 0.20 \\
- Technological environment. & 0.05 & 0.15 \\
- Vulnerability to inflation. & 0.05 & $\underline{0.15}$ \\
- The environmental impacts. & $\underline{0.05}$ & 3.50 \\
Total & 1.0 & 3 & 0.80 \\
Determinants of the competitive position of the company: & & 0.60 \\
- Market share. & 0.20 & 0.20 \\
- Market share growth. & 0.20 & 4 & 0.25 \\
- The quality of services provided. & 0.05 & 3 & 0.20 \\
- company's reputation. & 0.05 & 4 & 0.20 \\
- The effectiveness of the distribution network. & 0.05 & 5 & 0.20 \\
- The effectiveness of promotion. & 0.05 & 4 & 0.15 \\
- The volume of operations. & 0.05 & 4 & 0.30 \\
- The efficiency of operations. & 0.05 & 4 & 0.45 \\
- The relative cost. & 0.10 & 3 & 0.25 \\
- The availability of human resources. & 0.15 & 3 \\
- Administrative efficiency. & $\underline{0.05}$ & 3 & 3.60 \\
Total & 1.00 & 5 & \\
\hline
\end{tabular}

\subsubsection{Identifying the Appropriate Investment Strategy}

After Identifying the competitiveness ability of the company, it is represented by the total score (scale) graphically because of matrix coordinates. Accordingly, the identification of appropriate investment strategy for each market condition depends on the attractiveness and competitiveness of the company For example, if the low market attractiveness and competitiveness of the company is weak, the cautious sniping strategy is the appropriate investment strategy. Figure (3) marketing strategies according to multi factors matrix. 


\begin{tabular}{|c|c|c|c|c|}
\hline & 预 & $\begin{array}{l}\text { Selective reinforcement } \\
\text { Strategy }\end{array}$ & $\begin{array}{l}\text { Investment } \\
\text { and enhancement } \\
\text { Strategy }\end{array}$ & $\begin{array}{l}\text { condition protection } \\
\text { Strategy }\end{array}$ \\
\hline \multirow{3}{*}{ 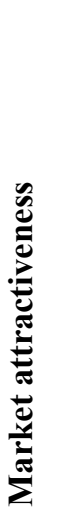 } & 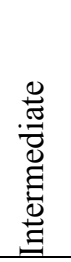 & $\begin{array}{l}\text { Limited expansion } \\
\text { (Harvest) } \\
\text { Strategy }\end{array}$ & $\begin{array}{l}\text { Selection of winning } \\
\text { Opportunities } \\
\text { strategy }\end{array}$ & $\begin{array}{l}\text { Selective investment } \\
\text { Strategy }\end{array}$ \\
\hline & \multirow[b]{2}{*}{ క్ } & $\begin{array}{l}\text { Cautious sniping } \\
\text { Strategy }\end{array}$ & $\begin{array}{l}\text { administration } \\
\text { strategy } \\
\text { aimed to profit }\end{array}$ & $\begin{array}{l}\text { Protection and } \\
\text { re-focus } \\
\text { Strategy }\end{array}$ \\
\hline & & weak & Intermediate & Strong \\
\hline
\end{tabular}

The company's ability

Figure 3. Marketing strategies according to multi factors matrix

We present below a summary of the most important methods that can be carried out by the company's administration in the case of adoption of any of the previous strategies (Field, Christopher ,2012).

1. Condition protection strategy: expanding investment in order to maximize growth rates. In addition, the concentration of efforts to keep points of strength.

2. Selective investment strategy: to intensify investment in the most attractive market segments. Moreover, build endogenous capacity to confront competition and to concentrate on the profit target by raising productivity levels

3. Protection and re-focus Strategy: investing in areas that achieve ongoing and rapid revenue, focusing on the most attractive market segments, and defending points of strength.

4. Investment and enhancement strategy: making efforts to get to market leadership, selecting some force elements to be strengthened, and overcoming weaknesses.

5. Selection of winning opportunities strategy: maintain the current investment program and protecting it. In addition, concentrating investments in market segments that offer the highest profit and lowest risks.

6. Administration strategy aimed to profit: to maintain the current situation for all sectors with higher profit.

\subsubsection{Analysis of Strengths' Weaknesses' Opportunities and Threats (S.W.O.T)}

After completion of the marketing review process, it is now necessary to evaluate the internal situation of the company with respect to the strengths and weaknesses compared with the opportunities and threats posed by the external environment. Among the most prominent advantages of this analysis is that it provides the marketing management in the company with a broader knowledge and deeper understanding through which it can develop thoughts and create possible methods to confront what may be laid down by potential environmental changes in the future. (Field, Christopher, 2012)

\subsection{Identifying the Target Market}

In the light of comprehensive review and analysis of both internal and external environmental forces of the company and identifying its competitive position, the next step in the process of planning the marketing strategy of the company is identifying the target market. The market can be defined as an area in which financial and credit needs of customers meet a range of goods provided by the company. The process of determining the potential market for the company is a difficult task and requires high levels of creative efforts. In practice, no company can meet the needs of all potential customers. Instead, companies resort to provide for certain sectors of customers, each of which represents apart of the overall market, as shown in Figure 3 and in order to evaluate the avail of target market, there must be an attempt to match the needs and the goods of customers with the goods and that applies for both institutions and individuals Respectively (Cox, \& Good, 2008) 


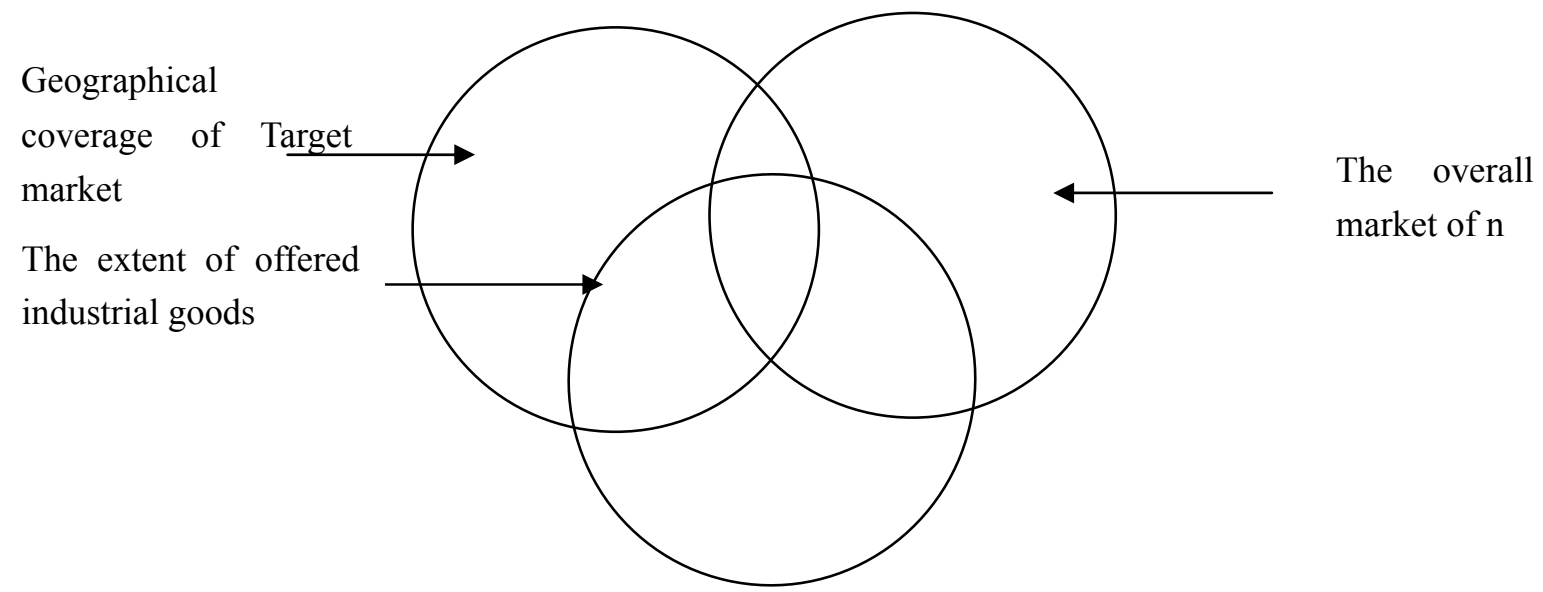

Figure 3. Identifying the target market

The companies differ regarding the standard or set of standards adopted in making this division. Some depend on the service standard and therefore specializes in the provision of certain goods only. While some companies are dedicated to certain geographic areas, others classify customers based on financial adequacy, and so on. Each market sector must be determined clearly, so that the following questions can be answered. Who are the clients that form the sector? What are the needs and the industrial goods of these clients? What are the goods that the company can offer with a high degree of sufficiency a profit and a lower degree of risks? What are the resources and capabilities required in the company to provide these services? How can the company manage these resources properly?

\section{Three Topic: Conclusions \& Recommendations}

\subsection{Conclusions}

Through what was mentioned in the theoretical framework and in the light of the reached results, these are the conclusions:

1. If the change for the better was studied well including all its aspects and can be implemented in a way that considers all factors, resisting it would increase the insistence to implement it and create a sense of pleasure and joy in developing and searching in addressing resistance points.

2. It remains for the one who came up with the idea and the supervisor on implementing it to think well of those who resist change as well as excusing them that they did not comprehend the idea, its positive aspects ,their lack of information and the method of projecting it. They also should not accuse them of deliberately disabling and resisting it unless that is evident which after a proper action is taken to deal with these behaviours.

3. Resistance to change and the idea of change may cause the correction of irregular paths.

4. Most of those in charge desire having enthusiasts to change who can study ideas and project it in proper methods as well as follow up their implementation in ways that prove their ability to know all aspects of the idea, physical, moral, organizational, behavioral.

5. Most employees want to facilitate the procedures of their work but they need a person to deliver the idea in a way that meets their mental responsibilities, qualification, experience, personal considerations, job positions, and how that will affect them and the organization in which they work, wither positively or negatively.

6. The reasons of resisting administrational change, because it is a direct threat of interests, are divided to organizational reasons. The change may occur in job positions, centres of power and influence in the company, the official communicating plans among its departments, which triggers fear for some employees that the importance of their positions and the work they do will be less important, or decreasing the level of company's competencies. There are also personal reasons, where some workers think that change threatens their personal interests in terms of affecting on their relationships and work methods which they are used to and unwilling to change, particularly if change requires large work charges and pressures and threatens the positions of their authority and power in company. In addition, they fear from future and are satisfied with current situation; some 
workers fear from inability to adapt with new changes because change may require learning new skill or acquiring knowledge and abilities, which they do not have before.

7. The objectives and reasons are not obvious. Resistance to change results from non-obviousness of its reasons and objectives as well as procedures and instructions related to change which workers implements or are influenced by. Furthermore, it results from workers' feeling that change is a matter of form not material one. It also results from workers who are not convinced by the ability of company to implement change and who do not recognize the necessity of change.

8. The resistance is not always a negative way, but is always the resistance of administrative change a pure negative way and not having any advantages? It is not always a negative way, it has some advantages. Some advantages of resistance are making those who implement change more accurate and willing to change. Objectives, reasons and importance of change have to be clarified for workers in order to not resist its application.

9. Human aspect should be taken into consideration. We need to study human behavior and its response of changing and development processes taking into account processing issue by planning and organizing. Therefore, we provide some behavioral recommendations in changing management including involving people in changing, providing people with continuous information and taking into consideration habits of workers and work values.

\subsection{Recommendations}

1. The researchers believe that the success of the resistance to change management in their work is accomplished by identifying the real causes of resistance to change, and then make solutions to reduce this resistance, such as:

2. Awareness and preparedness and configuration for employees of the need and the importance of change, for example, raising awareness and preparing employees when applying a new style of work, and as an example when they decide to implement the quality of work principle in the company.

3. The involvement of workers and convince them to change, where their participation in the process of determining condition and shape of change, and so workers are less resistant to change because they participated through their discussions and interventions in various stages.

4. Support employees to accommodate the change, by listening to the grumbling and complaints and training them to implement and absorb the change.

5. Using the way of negotiation and agreement by the management with some of the workers or their representatives to implement the change, such as negotiation and agreement with labor organizations to reduce wages or the introduction of different working methods.

6. The company's use of grooming and control methods so provide workers with information selectively, not all information.

7. The company's use of force and coercion methods to accept the change so the company's management use penalties and sanctions methods for all those who resist change, and threaten workers secretly or publicly

8. The need to work to identify the difficulties faced by the change: there is no doubt that the change management of the most difficult management tasks for leaders or managers manage because it requires the right man in the right place, and to apply the correct methods of work, also choosing the general structure of the company or its constituent administrative units, as well as the choice of the right technology for work and how to use them.

9. The need to determine the appropriate method to deal with resistance to change as the choice is determined by the state or the resistant to change position, as well as due to the personality of change makers and its supporters in higher administration in the company.

10. Researchers recommend of a conscious, creative and aware of the nature of human resistance to change and tendency to accept the current situation. Therefore, they have to, prepare and do everything in its power to reduce the resistance to change among workers, no doubt, that a small percentage of them will remain unconvinced to change no matter what the administration did, but it works on convincing them in order not to influence the change or other individuals.

\section{References}

Ali, A. Z. (2015). The management of modern marketing, Dar maasiera for publication, Jordan.

Ali, A. Z. (2016). Consumer behavior-A contemporary entrance to the 1st edition. University Book House, the 
eye-the United Arab Emirates.

Ali, A. Z., \& Adel, A. (2016). Foundations and scientific assets in Business Administration, Dar Yazouri Publishing, Jordan.

American Academy. (2002) Information Technology.

Baker, M. J. (2011). Bank Marketing Management. London: Macmillan.

Bilal, A. (2010). Strategic planning, Dar maasiera for publication, Jordan.

Cox, D. F., \& Good, R. (2008). How to build an marketing Information System. Harvard Business Review, 53.

Derek, F. C. (2009). Bank Strategic Management and Marketing. New York: John Wiley and Sons. Itd,.

Drucker, P. F. (2009). Long-Range Planning: Challenge to management. Management Science, 55(30).

Field, C. (2012). New Strategies for Marketing Information technology. London: Chapman \& Hall.

Grey, T. (2005). Managing Internal Controls. Accountancy Ireland, 37(6).

Joselyn, R. W., \& Humphries, K. D. (2011). An Introduction to Bank Marketing Planning. Washington, D.C.,: American Bankers Association.

Kotler, P. (2012). Marketing Management: Analysis, Planning, Implementation, and Control. Englewood Cliffs, N.J.: Prentice Hall Inc.

Kyle, B., \& Robert, W. S. (2009). An Economic Theory of GATT. The American Economic Review, 89(1).

Leontiasis, M. (2012). The Importance of Integrating Marketing planning with Corporate Planning. Journal of Business Research, 21.

Luck, D. J., Ferrell, O. C. (2007). Marketing strategy and plans (4th ed.). Englewood Cliffs, N. J.: Prentice-Hall, inc.

Marsh, J. R. (2012). Managing Financial Services Marketing. London: Pilman Publishing.

Mcnurlin, B., \& Sprague, R. (2011). Information Systems Management in Practice. Englwood Cliffs, N.J. Prentice -Hall Inc.

Porter, M. F. (2011). Competitive strategy. New York: Macmillan.

\section{Copyrights}

Copyright for this article is retained by the author(s), with first publication rights granted to the journal.

This is an open-access article distributed under the terms and conditions of the Creative Commons Attribution license (http://creativecommons.org/licenses/by/4.0/). 